ARTICLE

https://doi.org/10.1038/s414.67-020-14543-2

\title{
Versatile cobalt-catalyzed regioselective chain-walking double hydroboration of 1 , n-dienes to access gem-bis(boryl)alkanes
}

Ming $\mathrm{Hu}^{1} \&$ Shaozhong $\mathrm{Ge} \mathbb{1}^{1 *}{ }^{1 \star}$

Double hydroboration of dienes is the addition of a hydrogen and a boryl group to the two double bonds of a diene molecule and represents a straightforward and effective protocol to prepare synthetically versatile bis(boryl)alkanes, provided that this reaction occurs selectively. However, this reaction can potentially yield several isomeric organoboron products, and it still remains a challenge to control the regioselectivity of this reaction, which allows the selective production of a single organoboron product, in particular, for a broad scope of dienes. By employing a readily available cobalt catalyst, here we show that this double hydroboration yields synthetically useful gem-bis(boryl)alkanes with excellent regioselectivity. In addition, the scope of dienes for this reaction is broad and encompasses a wide range of conjugated and non-conjugated dienes. Furthermore, mechanistic studies indicate that this cobalt-catalyzed double hydroboration occurs through boryl-directed chain-walking hydroboration of alkenylboronates generated from anti-Markovnikov 1,2-hydroboration of 1,n-diene. 
O rganoboronates are versatile building blocks for chemical synthesis because of their diverse reactivity in organic reactions ${ }^{1,2}$. As an important family of organoboron compounds, gem-bis(boryl)alkanes have recently gained increasing attention in organic synthesis due to their unique reactivity ${ }^{3-7}$. For example, different reactivity of the two boryl groups in gembis(boryl)alkanes allows stepwise functionalization of their two C-B bonds ${ }^{8-10}$. Interestingly, gem-bis(boryl)alkanes can generate two types of carboanions, monoboryl- or gem-bis(boryl)-functionalized carboanions, via deprotonation by LiTMP (lithium tetramethylpiperidide) or alkoxide-induced deborylation ${ }^{11,12}$. Over past decades, series of catalytic reactions have been developed to access these gem-bis(boryl) compounds ${ }^{13-17}$, such as double hydroboration of alkynes ${ }^{18-20}$, diborylation of alkenes ${ }^{21,22}$, hydroboration of 1-borylalkene $\mathrm{e}^{23-25}$, or $\mathrm{C}-\mathrm{H}$ borylation reactions ${ }^{26-29}$. Nevertheless, a general and practical approach that combines high catalytic activity, easy accessibility and handling of starting materials, and structural diversity of gem-bis(boryl) products is still lacking.

Metal-catalyzed hydroboration of 1,3-dienes has been developed into selective approaches to prepare allylic or homoallylic organoboron compounds ${ }^{30-35}$. However, double hydroboration of 1,3-dienes has been barely studied, mainly because alkenylboron products from the first hydroboration contain an unactivated internal alkene that does not readily undergo the second hydroboration. There was only one early example of rhodium-catalyzed double hydroboration of 1,3-dienes reported by Hayashi, and this reaction selectively afforded 1,3-bis(boryl) alkane products ${ }^{36}$. Catalysts for selective double hydroboration of 1,n-dienes to synthesize gem-bis(boryl)alkanes still remains unknown.

Recently, metal-mediated chain walking has been emerging as a useful tool for remote functionalization of organic molecules $^{37-54}$. The directions for chain walking can be controlled by catalysts or directing groups in organic substrates. For example, aryl or boryl groups in the substrates can direct the chain walking towards them $46,48,51,54$. Therefore, double hydroboration of 1 , n-dienes can be potentially developed into an effective and selective protocol to prepare gem-bis(boryl)alkanes, provided that a trifunctional catalyst can be identified to catalyze these three transformations: selective hydroboration of $1, n$-dienes to produce alkenylboronates, the isomerization of alkenylboronates to 1borylalkenes, and the subsequent hydroboration of 1-borylalkenes to yield gem-bis(boryl)alkanes (Fig. 1).

In recent years, cobalt compounds have been extensively studied as catalysts for hydroboration and isomerization of alkenes $^{55-63}$. In 2015, Chirik and coworkers showed one example of cobalt-catalyzed hydroboration of a boryl-containing terminal alkene to give a gem-bis(boryl)alkane product by taking the advantage of boryl-directed alkene isomerization ${ }^{59}$. During our continuous efforts in developing cobalt-catalyzed hydroboration of unsaturated hydrocarbons ${ }^{64-66}$, we become interested in identifying a selective cobalt catalyst for double hydroboration of 1,n-dienes to synthesize gem-bis(boryl)alkanes. We envisioned that it would be more challenging to develop a selective double hydroboration of aryl-substituted 1,n-dienes because both aryl and boryl groups in alkenylboronate products of the first hydroboration can control the direction of subsequent alkene isomerization, which would probably decrease the selectivity for the second hydroboration. Indeed, such decreased selectivity has been encountered in a recent study on $\mathrm{NiH}$-catalyzed remote hydroarylation of a phenyl-containing alkenylboronate ${ }^{54}$. Here, we show that double hydroboration of these $1, n$-dienes takes place to yield synthetically versatile gem-bis(boryl)alkanes with high regioselectivity in the presence of $\mathrm{Co}(\mathrm{acac})_{2}$ and 1,2-bis (dicyclohexylphosphino)ethane (dcpe).

\section{Results}

Evaluation of reaction conditions. We chose the reaction of $(E)$ octa-3,7-dien-1-ylbenzene (1a) with HBpin to identify a cobalt catalyst and the conditions that favor the formation of the gembis(boryl)alkane product 2a (Fig. 2). The cobalt catalysts we intended to evaluate were generated in situ from $\mathrm{Co}(\mathrm{acac})_{2}$ and bisphosphine ligands and activated by the reaction with HBpin. In general, the targeted double hydroboration reactions were conducted with $2 \mathrm{~mol} \%$ cobalt catalyst in the presence of 2.5 equivalents of $\mathrm{HBpin}$ for $4 \mathrm{~h}$ at $100^{\circ} \mathrm{C}$. The selected examples of these reactions are summarized in Fig. 2.

The reaction conducted with $\mathrm{Co}(\mathrm{acac})_{2}$ and dppe proceeded sluggishly to very low conversion $(<5 \%)$ of $\mathbf{1 a}$ and the desired product $\mathbf{2 a}$ was not formed (Fig. 2, entry 1). The reaction catalyzed by $\mathrm{Co}(\mathrm{acac})_{2}$ and dppbz occurred to a low conversion (33\%) of 1a and only a trace amount of $\mathbf{2 a}$ was detected together with several other isomeric $1, \mathrm{n}$-dienes that were resulted from the isomerization of 1a (Fig. 2, entry 2). The reactions of $\mathbf{1 a}$ with HBpin afforded alkenylboronate $\mathbf{2} \mathbf{a}^{\prime}$ as a major product when conducted with $\mathrm{Co}(\mathrm{acac})_{2}$ and dppp or dppb ligand (Fig. 2, entries 3 and 4). The reactions run with $\mathrm{Co}(\mathrm{acac})_{2}$ and dppf, dpephos, or xantphos afforded eight isomeric bis(boryl)alkane products (Fig. 2, entries 5-7), and the selectivity for the desired product 2 a was only low to modest $(28-56 \%)$. To our delight, the reaction catalyzed by $2 \mathrm{~mol} \% \mathrm{Co}(\mathrm{acac})_{2} / \mathrm{dcpe}$ produced $2 \mathrm{a}$ in good yield $(72 \%)$ and high regioselectivity (95\% rr, Fig. 2, entry 8 ). In particular, the reaction conducted with $3 \mathrm{~mol} \%$ catalyst afforded $\mathbf{2 a}$ in high isolated yield (76\%) with excellent regioselectivity (97\% rr, Fig. 2, entry 9). We also tested various temperatures for this double hydroboration reaction catalyzed by $\mathrm{Co}(\mathrm{acac})_{2} / \mathrm{dcpe}$. Similar results were obtained for the reactions run at $100^{\circ} \mathrm{C}$ and $80^{\circ} \mathrm{C}$ (Fig. 2, entries 8 and 10). Further lowering the temperature to $50^{\circ} \mathrm{C}$ led to a lower yield of $2 \mathrm{a}$ with a diminished regioselectivity (Fig. 2, entry 11). Particularly, the reaction performed at room temperature afforded only the alkenylboronate product $\mathbf{2} \mathbf{a}^{\prime}$, which was formed from hydroboration of the terminal double bond of 1a (Fig. 2, entry 12).

Substrate scope of conjugated and non-conjugated 1,n-dienes. With the identified cobalt catalyst and reliable conditions in hand, we studied the scope of $1, n$-dienes that undergo this cobaltcatalyzed double hydroboration for the synthesis of gem-bis (boryl)alkanes, and the results are summarized in Fig. 3. In general, a wide range of non-conjugated $(Z / E)-1, \mathrm{n}$-dienes $(\mathbf{1} \mathbf{a}-\mathbf{1 h})$ and conjugated $(Z / E)-1,3$-dienes (1i-1al) smoothly reacted with $\mathrm{HBpin}$ in the presence of $1 \mathrm{~mol} \% \mathrm{Co}(\mathrm{acac})_{2}$ and 1 mol\% dcpe, yielding the corresponding gem-bis(boryl)alkanes $(\mathbf{2 a}-\mathbf{2 a l})$ in modest to high isolated yields $(58-88 \%)$ with excellent regioselectivity (up to $99 \%$ ). Noticeably, carbocyclic products resulted from cyclization of 1,6-diene 1c were not detected.

The scope of 1,n-dienes encompasses both alkyl- and arylsubstituted 1,n-dienes with substituents at various positions (e.g. 1g-1q). Particularly, the double hydroboration of $1, n$-dienes (1h and 1l-1q) containing 1,1-disubstituted alkene units

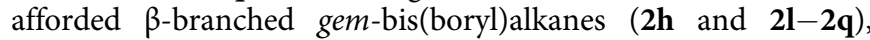
which are not accessible via double hydroboration of terminal alkynes. In addition, 1,3-dienes containing ortho-substituted aryl groups also smoothly reacted under identified conditions to afforded the corresponding gem-bis(boryl)alkanes (2t and $\mathbf{2 u}$ ) in high isolated yields. This cobalt-catalyzed double hydroboration can tolerate a range of functional groups, such as ether (2d and $\mathbf{2 v}$ ), tertiary amine (2y), thioether (2z), fluoride (2ab), carboxylic ester (2ac), and acetal (2ad). Nitrogen- and oxygen-containing 1,3-dienes also reacted to afford the desired products (2aj-2al) in high isolated yields. 


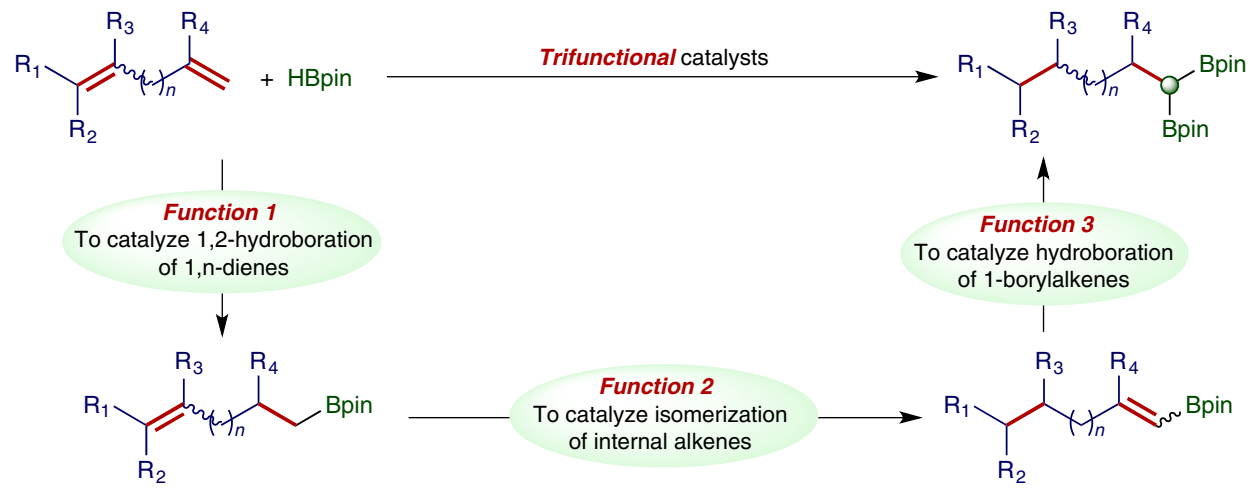

Fig. 1 Hydroboration of dienes. Trifunctional catalysts for chain-walking double hydroboration of 1,n-dienes.

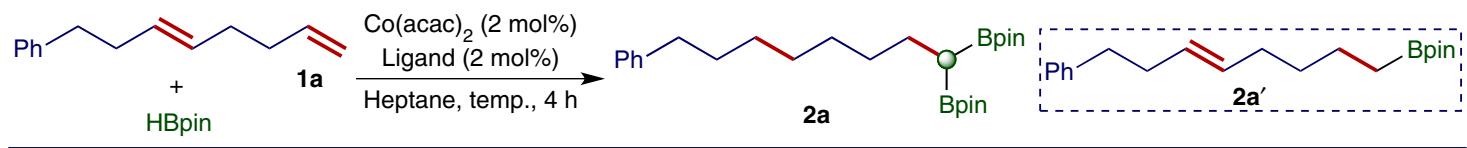

\begin{tabular}{|c|c|c|c|c|c|c|}
\hline 1 & dppe & 100 & $<5$ & -- & -- & \multirow{3}{*}{$\begin{array}{c}\mathrm{Ph}_{2} \mathrm{P} Y_{n} \mathrm{PPh}_{2} \\
n=2, \mathrm{dppe} \\
n=3, \mathrm{dppp} \\
n=4, \mathrm{dppb}\end{array}$} \\
\hline 2 & dppbz & 100 & 33 & -- & -- & \\
\hline 3 & dppp & 100 & 56 & $<2$ & -- & \\
\hline 4 & dppb & 100 & $>99$ & $<2$ & -- & \\
\hline 5 & dppf & 100 & $>99$ & 19 & 28:72 & \\
\hline 6 & dpephos & 100 & $>99$ & 26 & $55: 45$ & \\
\hline 7 & xantphos & 100 & $>99$ & 49 & $56: 44$ & \\
\hline 8 & dcpe & 100 & $>99$ & $72(64)$ & $95: 5$ & \\
\hline $9^{*}$ & dcpe & 100 & $>99$ & $82(76)$ & $97: 3$ & \\
\hline 10 & dcpe & 80 & $>99$ & 69 & $98: 2$ & \\
\hline 11 & dcpe & 50 & $>99$ & 26 & $78: 22$ & \\
\hline 12 & dcpe & $\mathrm{RT}$ & $>99$ & $<2$ & -- & dppf \\
\hline
\end{tabular}

Fig. 2 Evaluation of conditions for cobalt-catalyzed double hydroboration of 1,5-diene 1a. Reaction conditions: 1a (0.200 mmol), HBpin ( $0.500 \mathrm{mmol})$, $\mathrm{Co}(\mathrm{acac})_{2}(4.0 \mu \mathrm{mol})$, ligand $(4.0 \mu \mathrm{mol})$, heptane $(0.5 \mathrm{~mL}), 4 \mathrm{~h}$, yield was determined by $\mathrm{GC}$ (gas chromatography) analysis using tridecane as internal standard and yield in parentheses was isolated yield of $\mathbf{2 a} .{ }^{*} r$ is regioisomeric ratio and represents the ratio of the desired gem-bis(boryl)alkane product to the sum of all other bis(boryl)alkane isomers as determined by gas chromatography analysis. ${ }^{\star} 3 \mathrm{~mol} \%$ cobalt catalyst.

In addition, we also tested this cobalt catalyst for hydroboration reactions of dienes containing two internal or two terminal carbon-carbon double bonds, and the results are shown in Fig. 4. Under standard conditions, bis(alkyl)-substituted 1,3-diene 1am reacted smoothly with HBpin to afford gem-bis(boryl)alkane product $\mathbf{2 a e}$ in $51 \%$ isolated yield (Fig. 4a). Product 2ae contains two Bpin groups on the terminal $\mathrm{sp}^{3}$-carbon, indicating the isomerization of both internal double bonds to terminal double bonds. The hydroboration reactions of aryl,alkyl- or aryl,aryldisubstituted 1,3-dienes 1an and 1ao produced benzylic boronates 3 and 4, respectively, in high yields (Fig. 4b, c). These benzylic boronate products were formed by cobalt-catalyzed sequential hydroboration and hydrogenation of 1 an and 1ao. The double hydroboration of 1,5-hexadiene 1ap, a diene containing two terminal double bonds, yielded two bis(boryl)alkane products, 1,1-bis(boryl)hexane 2ap and 1,6-bis(boryl)hexane 2ap', and the ratios of these two products were temperature dependent. For example, the reaction conducted at $100^{\circ} \mathrm{C}$ afforded 1,1-bis(boryl)hexane 2ap as the major product with 2ap:2ap' of 76:24, and gem-bis(boryl)alkane product 2ap was isolated in $63 \%$ yield (Fig. 4d). However, the corresponding reaction run at room temperature gave 1,6-bis(boryl)hexane 2ap' in $81 \%$ isolated yield with high regioselectivity (2ap:2ap' $=7: 93$, Fig. 4e).

Synthetic utilities. This cobalt-catalyzed chain-walking double hydroboration of $1, n$-dienes can be conducted on gram-scales with a decreased catalyst loading. For example, the reaction of (Z/E)-buta-1,3-dien-1-ylbenzene 1s $(Z: E=45: 55)$ with HBpin on a $8.0-\mathrm{mmol}$ scale proceeded to full conversion of $1 \mathrm{~s}$ in the presence of $0.5 \mathrm{~mol} \% \mathrm{Co}(\mathrm{acac})_{2} / \mathrm{dcpe}$ and afforded the desired product 2 s $(2.53 \mathrm{~g})$ in $82 \%$ isolated yield (Fig. $5 \mathrm{a}$ ). We subsequently show the utility of gem-Bis(boryl)alkane $2 \mathrm{~s}$ as a versatile building block in organic synthesis by conducting a series of organic transformations with $2 s$ (Fig. $5 b-f$ ). For example, 2s could undergo a Boron-Wittig reaction with an aldehyde to afford ketone 5 after oxidative workup with $\mathrm{NaBO}_{3} \bullet 4 \mathrm{H}_{2} \mathrm{O}$ (ref. ${ }^{10}$ ) (Fig. 5b). 2s could also be used as an alkylating reagent for the alkylation of quinoline $\mathrm{N}$-oxide to prepare 2-alkylquinoline 6 


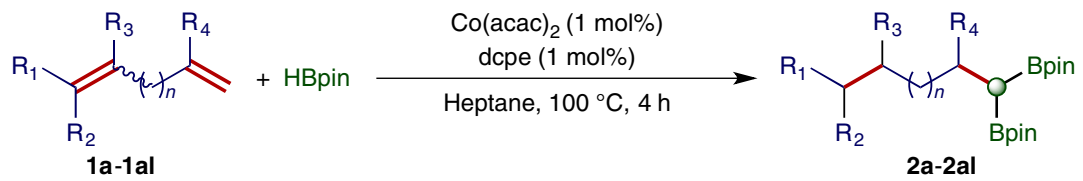

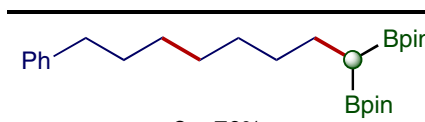

2a, $76 \%$<smiles>c1ccc(COCCCCCCOc2ccccc2)cc1</smiles>

2d, $62 \%$<smiles>O=[13C]C(=O)OCCCC(c1ccccc1)c1ccccc1</smiles><smiles>CC(C)=CCCC(C)CCOCc1ccccc1</smiles>

$2 k, \stackrel{8}{ } 48 \%$<smiles></smiles>

$\mathrm{R}=\mathrm{H}, \mathbf{2 s}, 88 \%$

$\mathrm{R}=\mathrm{OMe}, \mathbf{2 t}, \mathbf{7 9} \%$

$\mathrm{R}=\mathrm{CF}_{3}, \mathbf{2 u}, 76 \%$<smiles>CC(=O)Oc1ccc(CCCOCc2ccccc2)cc1</smiles><smiles>CC(C)CCCOC(=O)OCc1ccccc1</smiles>

2ae, $n=4,75 \%$

2af, $n=5,78 \%$

2ag, $n=7,76 \%$

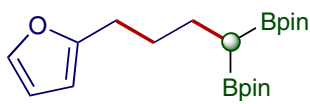

2aj, $72 \%$<smiles>O=[Bi](OCCCCCc1ccccc1)c1ccccc1</smiles>

2b, ${ }^{\#} 60 \%$<smiles>c1ccc(COC(Cc2ccccc2)OCCCCCC2CCCCC2)cc1</smiles>

$2 e, 68 \%$

2a-2al<smiles>CCCCCCCCCCOCc1ccccc1</smiles>

2c, $69 \%$<smiles>c1ccc(CCCCCOC(Cc2ccccc2)c2ccccc2)cc1</smiles>

2f, ${ }^{\#} 67 \%$<smiles>CC(CCCc1ccccc1)OC(=O)Cc1ccccc1</smiles>

2h, ${ }^{\#} 59 \%$<smiles>[R]C(CCc1ccccc1)OCc1ccccc1</smiles>

$\mathrm{R}=\mathrm{Me}, \mathbf{2 l}, \mathbf{7 0} \%$

$\mathrm{R}=\mathrm{Et}, \mathbf{2 m}, \mathbf{6 3} \%$

$\mathrm{R}=n$-hex, 2n, $71 \%$

$\mathrm{R}=\mathrm{Ph}, \mathbf{2 0}, 58 \%$<smiles>COc1cccc(CCCOC(Cc2ccccc2)Cc2ccccc2)c1</smiles>

$2 v, 80 \%$<smiles>c1ccc(CC(Cc2ccccc2)OCCCc2ccc(C3OCCO3)cc2)cc1</smiles>

2ad, $79 \%$<smiles>c1ccc(CCOC(Cc2ccccc2)Cc2ccccc2)cc1</smiles>

2ah, $71 \%$<smiles>c1ccc(CCOC(CCCc2cc3ccccc3o2)Cc2ccccc2)cc1</smiles>

2ak, $54 \%$<smiles>O=C(CCC(c1ccccc1)c1ccccc1)c1ccccc1</smiles>

2i, $73 \%$<smiles>CC(CCC1CCCCC1)OC(=O)Cc1ccccc1</smiles>

$2 p, 79 \%$<smiles>CCCCCCCOC(Cc1ccccc1)Cc1ccccc1</smiles>

2q, $61 \%$<smiles>CC(CC(c1ccccc1)c1ccccc1)OC(=O)Cc1ccccc1</smiles><smiles>[R]c1ccc(CCCOC(Cc2ccccc2)Cc2ccccc2)cc1</smiles>

$\mathrm{R}=\mathrm{Me}, \mathbf{2 w}, \mathbf{8 3} \%$

$\mathrm{R}=\mathrm{OMe}, \mathbf{2 x}, 85 \%$

$\mathrm{R}=\mathrm{NMe}_{2}, \mathbf{2 y}, \mathbf{8 3} \%$

$\mathrm{R}=\mathrm{SMe}, \mathbf{2 z}, 67 \%$

$\mathrm{R}=\mathrm{t} \mathrm{Bu}, \mathbf{2 a a}, 82 \%$

$\mathrm{R}=\mathrm{F}, \mathbf{2} \mathbf{a b}, \mathbf{7 9} \%$<smiles>c1ccc(CCCCCOCc2ccccc2)cc1</smiles>

2ai, $72 \%$<smiles>Cn1cc(CCCOC(Cc2ccccc2)Cc2ccccc2)c2ccccc21</smiles>

2al, $79 \%$

Fig. 3 Scope of 1,n-dienes. Reaction conditions: 1,n-diene $(0.300 \mathrm{mmol}), \mathrm{HBpin}(0.750 \mathrm{mmol}), \mathrm{Co}(\mathrm{acac}) 2(3.0 \mu \mathrm{mol})$, dcpe $(3.0 \mu \mathrm{mol})$, heptane $(0.5 \mathrm{~mL})$, $100^{\circ} \mathrm{C}, 4 \mathrm{~h}$, and isolated yields. ${ }^{*} 3 \mathrm{~mol} \%$ catalyst; $\& 80^{\circ} \mathrm{C}$.

(ref. ${ }^{67}$ ) (Fig. 5c). In addition, the carbanion generated by the deprotonation of $2 s$ with LiTMP, NaHMDS, or $\mathrm{NaO}^{t} \mathrm{Bu}$ reacted with iodomethane or 5-bromopent-1-ene to afford borylfunctionalized alkenes 7, 8, and 9, respectively ${ }^{11}$ (Fig. 5d-f). Furthermore, gem-bis(boryl)alkane $\mathbf{2 s}$ readily underwent $\mathrm{Pd}$ catalyzed Suzuki-Miyaura coupling with 4-iodoanisole to give alkylboronate 10 in $81 \%$ isolated yield (Fig. $5 \mathrm{~g}$ ).

\section{Discussion}

We subsequently conducted a series of experiments to gain insights into the mechanism of this cobalt-catalyzed double hydroboration reactions of $1, \mathrm{n}$-dienes, and the results of these experiments are summarized in Fig. 6. Similar to monohydroboration of 1,5-diene 1a at room temperature (Fig. 2, entry 12 ), monohydroboration of 1,3 -diene $1 \mathrm{~s}$ with 1.1 equiv. of $\mathrm{HBpin}$ occurred to completion in $30 \mathrm{~min}$ at room temperature and afforded alkenylboronate 11 s selectively (Fig. 6a). Subsequent heating the reaction mixture at $100^{\circ} \mathrm{C}$ for $2 \mathrm{~h}$ resulted in the isomerization of $11 \mathrm{~s}$ to a mixture of alkenylboronates $11 \mathrm{~s}, 11 \mathrm{~s}^{\prime}$, and $11 \mathbf{s}^{\prime \prime}$ with a ratio of 51:17:32 (Fig. 6a). We then tested a mixture of these alkenylboronates for hydroboration with HBpin in the presence of $1 \mathrm{~mol} \%$ of $\mathrm{Co}(\mathrm{acac})_{2} / \mathrm{dcpe}$, and all these isomeric alkenylboronates were converted to gem-bis(boryl)alkane $2 \mathrm{~s}$ in high yield (Fig. 6b). The conversion of 11s, 11s', and $11 \mathrm{~s}^{\prime \prime}$ to a single product $2 \mathrm{~s}$ indicates that boryl group has a stronger directing ability for this cobalt-catalyzed chain-walking hydroboration than phenyl group, which may stem from the interaction of the $d$-electrons of the cobalt catalyst with the empty $p$-orbital on boron ${ }^{68}$.

A control experiment of this double hydroboration was conducted with a substrate containing an oxygen-tethered 1,6-diene 
a

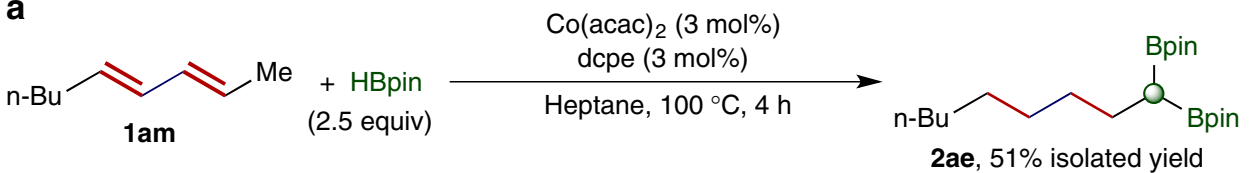

b<smiles>CC=CC=Cc1ccccc1</smiles>

$\mathrm{Co}(\mathrm{acac})_{2}(3 \mathrm{~mol} \%)$

dcpe (3 $\mathrm{mol} \%)$

Heptane, $100^{\circ} \mathrm{C}, 4 \mathrm{~h} \longrightarrow \mathrm{Me}$

$3,72 \%$ isolated yield

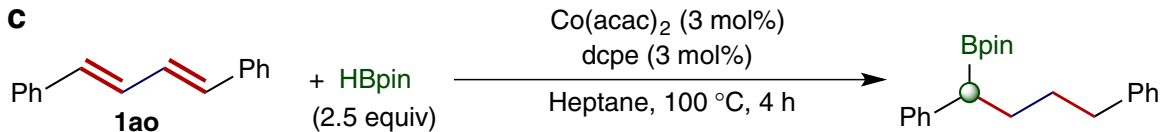

4, $79 \%$ isolated yield

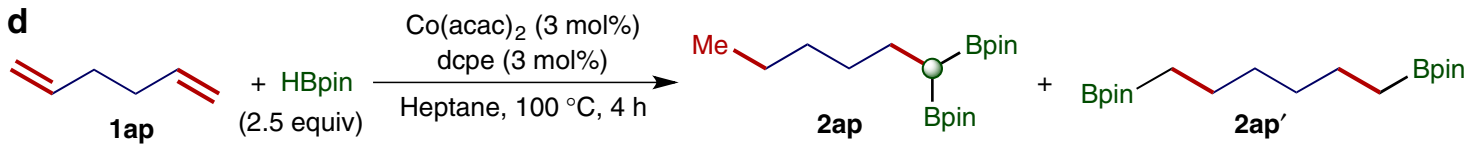

2ap, 63\% isolated yield (2ap:2ap' $=76: 24)$

e

$\mathrm{Co}(\mathrm{acac})_{2}(3 \mathrm{~mol} \%)$<smiles>C=CCCC=[C+]Cc1ccccc1</smiles>
dcpe (3 mol\%)

Heptane, rt, $4 \mathrm{~h}$

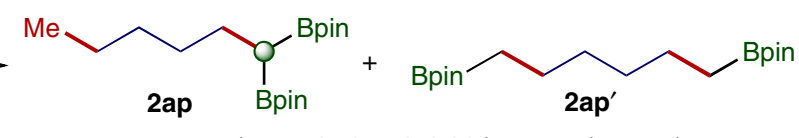

2ap', 81\% isolated yield (2ap:2ap' $=7: 93)$

Fig. 4 Hydroboration of dienes containing two internal double bonds or two terminal double bonds. a Double hydroboration of diene 1am. $\mathbf{b}$ Sequential hydroboration/hydrogenation of diene $\mathbf{1 a n}$. c Sequential hydroboration/hydrogenation of diene 1ao. d Double hydroboration of diene $\mathbf{1 a p}$ at $100{ }^{\circ} \mathrm{C}$. e Hydroboration of diene 1ap at room temperature.

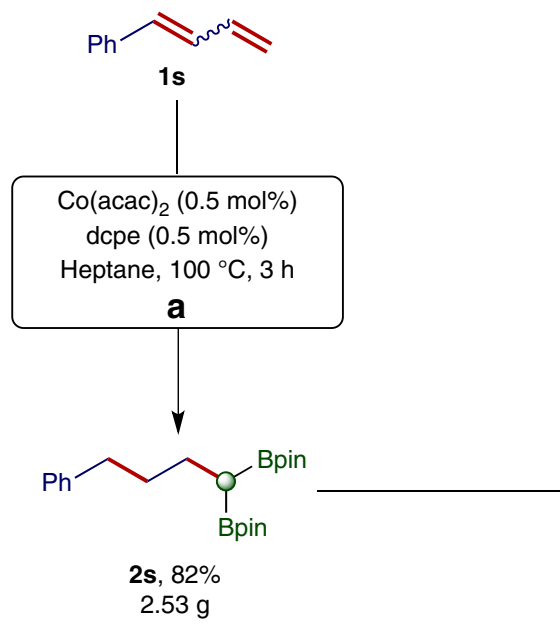
b $1 . \operatorname{LiTMP}(1.0$ equiv) THF, $-78-0^{\circ} \mathrm{C}, 4 \mathrm{~h}$
2. furan-2-carbaldehyde (1.05 equiv)
3. $\mathrm{NaBO}_{3} \bullet 4 \mathrm{H}_{2} \mathrm{O}$ (9 equiv) $\mathrm{H}_{2} \mathrm{O} / \mathrm{THF}, \mathrm{rt}, 2 \mathrm{~h}$<smiles>O=C(CCCc1ccccc1)Cc1ccco1</smiles>

C Quinoline $\mathrm{N}$-oxide ( 0.5 equiv) $\mathrm{NaOMe}$ (3.0 equiv)

Toluene, $80^{\circ} \mathrm{C}, 4 \mathrm{~h}$<smiles>c1ccc(CCCCc2ccc3ccccc3n2)cc1</smiles>

d LiTMP (2.0 equiv) Mel (1.0 equiv)

THF, $40^{\circ} \mathrm{C}, 12 \mathrm{~h}$
e NaHMDS (3.0 equiv.) 5-bromo-pent-1-ene (1.2 equiv)
THF, rt, $12 \mathrm{~h}$
f $\mathrm{NaO}^{t} \mathrm{Bu}$ (3.0 equiv) 5-bromo-pent-1-ene (1.2 equiv)
THF, rt, $12 \mathrm{~h}$<smiles>C=CCCCC(Cc1ccccc1)(Cc1ccccc1)OCCCc1ccccc1</smiles>
8, $73 \%$<smiles>CC(CCCc1ccccc1)(Cc1ccccc1)Cc1ccccc1</smiles>

7, $83 \%$

g $\mathrm{Pd}\left(\mathrm{P}^{t} \mathrm{Bu}_{3}\right)_{2}(5 \mathrm{~mol} \%)$ 4-iodoanisole (1.0 equiv) $\mathrm{KOH}$ (4.5 equiv)

$\mathrm{H}_{2} \mathrm{O} / 1$,4-dioxane, rt, $2 \mathrm{~h}$

Fig. $\mathbf{5}$ Gram-scale synthesis of gem-bis(boryl)alkane $\mathbf{2 s}$ and its further transformations. a Gram-scale synthesis of $\mathbf{2 s}$. b Synthesis of $\mathbf{5}$. c Synthesis of $\mathbf{6}$. d Synthesis of 7. e Synthesis of $\mathbf{8}$. $\mathbf{f}$ Synthesis of 9. $\mathbf{g}$ Synthesis of $\mathbf{1 0 .}$ 
a Monohydroboration of diene 1s, followed by isomerization of homoallylic boronate $(E)-11 \mathrm{~s}$ :

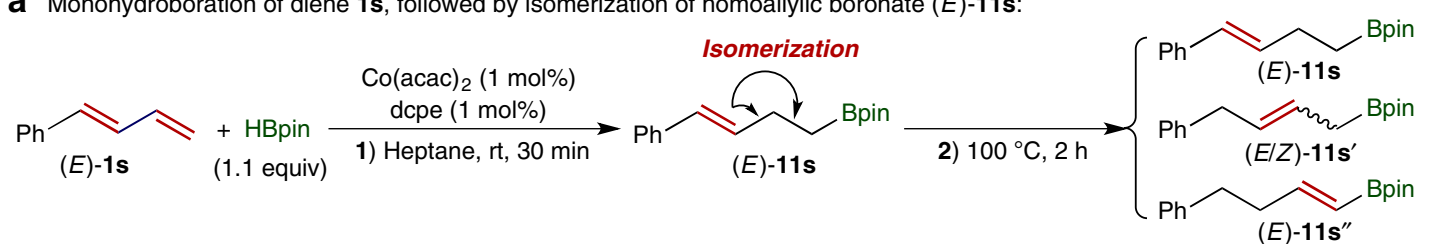

$(E)-\mathbf{1 1 s}:(E / Z)-\mathbf{1 1} \mathbf{s}^{\prime}:(E)-\mathbf{1 1} \mathbf{s}^{\prime \prime}=51: 17: 32$

b Hydroboration of a mixture of alkenylboronates:

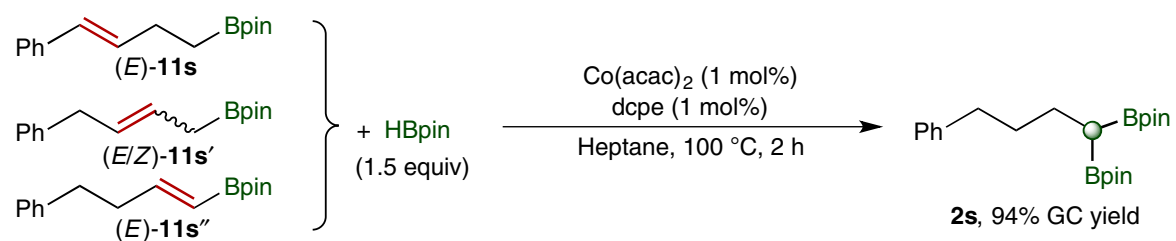

$(E)-11 s:(E)-11 s^{\prime}:(Z)-11 s^{\prime}: 11 s^{\prime \prime}=4: 3: 1: 2$

C Hydroboration of O-tethered 1,6-diene:

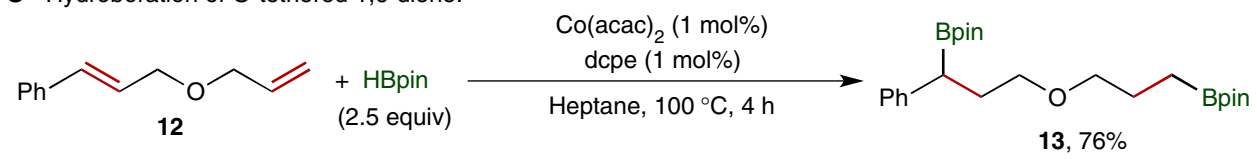

d Deuterium-labelling experiments:

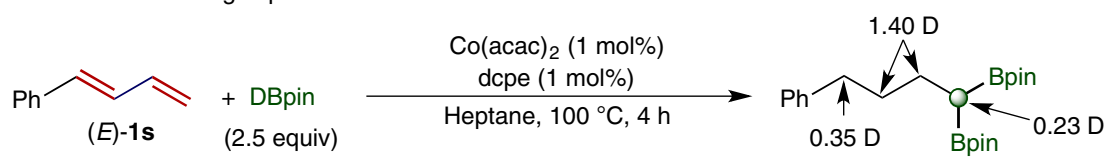

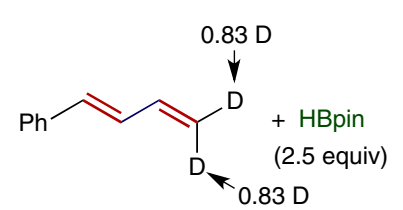

$(E)-1 s-D$

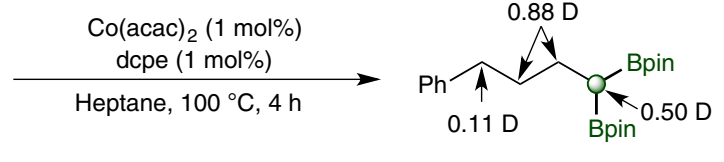

$2 s-D, 76 \%$ isolated yield

e Crossover experiment:<smiles>[Y10]C(C)(F)c1ccc(C=CC=C)cc1</smiles>

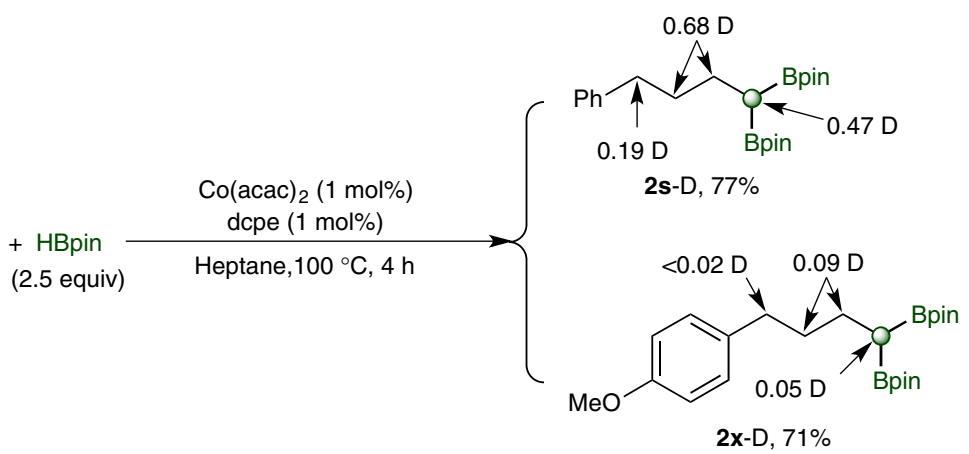

Fig. 6 Deuterium-labeling experiment and control experiments. a Monohydroboration of diene 1s and isomerization of alkenylboronate (E)-11s.

b Hydroboration of a mixture of alkenylboronates. c Hydroboration of O-tethered 1,6-diene 12. d Deuterium-labeling experiments. e Crossover experiment.

12 (Fig. 6c). This reaction afforded 1,7-bis(boryl)alkane 13 and chain-walking double hydroboration was not observed. This suggests that the chain walking takes place through reversible $\beta$ hydrogen elimination and reinsertion steps. A deuterium-labeling experiment of the double hydroboration of 1,3-diene $(E)$-1s was then conducted with DBpin, and deuterium incorporation at all positions of the aliphatic chain of gem-bis(boryl)alkane $2 \mathrm{~s}$-D was observed (Fig. 6d). When the deuterium-labeling experiment was performed with (E)-1s-D and HBpin, deuterium scrambling at all positions of the aliphatic chain of $2 s-\mathrm{D}$ was observed as well (Fig. 6d). In addition, when a crossover experiment of this double hydroboration was run with $(E)-\mathbf{1 s}-\mathrm{D}$ and $(E / Z)-\mathbf{1} \times$, similar deuterium incorporation and deuterium scrambling map was also observed for gem-bis(boryl)alkane products $2 \mathrm{~s}-\mathrm{D}$ and $2 \times-\mathrm{D}$ (Fig. 6e). The results of this crossover experiment indicate that dissociation and re-association of $\mathrm{Co}-\mathrm{H} / \mathrm{D}$ from the Co-H/Dolefin complex occurs during the chain walking process.

We then tested this cobalt catalyst, $\mathrm{Co}(\mathrm{acac})_{2} / \mathrm{dcpe}$, for chainwalking hydroboration of phenyl- and boryl-containing alkenes with double bonds at various positions, and the results are summarized in Fig. 7. (E)-But-1-en-1-ylbenzene (14) reacted smoothly with 1.5 equivalents HBpin in the presence of $3 \mathrm{~mol} \%$ 
a<smiles>CCC=Cc1ccccc1</smiles>

b

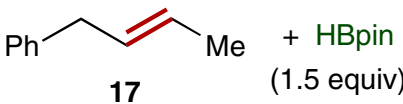

C<smiles>C=CCCc1ccccc1</smiles>

18

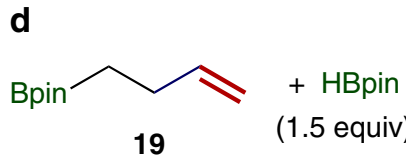

e<smiles>C=CCCc1ccccc1</smiles>

18

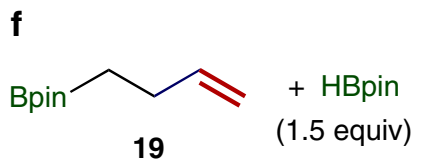

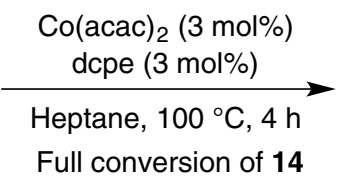

Full conversion of $\mathbf{1 4}$

$\mathrm{Ph}$<smiles>CCCC(Cc1ccccc1)c1ccccc1</smiles>

Product ratio 15:16 $=96: 4$<smiles>CCCC(C(=O)OCCCCCCCCCCCc1ccccc1)c1ccccc1</smiles>

Full conversion of 17

Product ratio 15:16 $=61: 39$

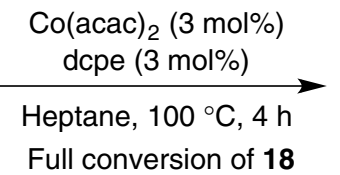<smiles>CCCC(C(=[N+])c1ccccc1)c1ccccc1</smiles>

Product ratio $15: 16=38: 62$<smiles>CCCC(Cc1ccccc1)Cc1ccccc1</smiles>

Full con

Product ratio 20:21 $=64: 36$

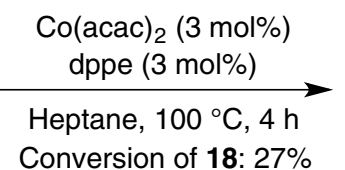<smiles>CCCC(C(=O)OC#CCCCCCCCc1ccccc1)c1ccccc1</smiles>

Product ratio 15:16 $=2: 98$
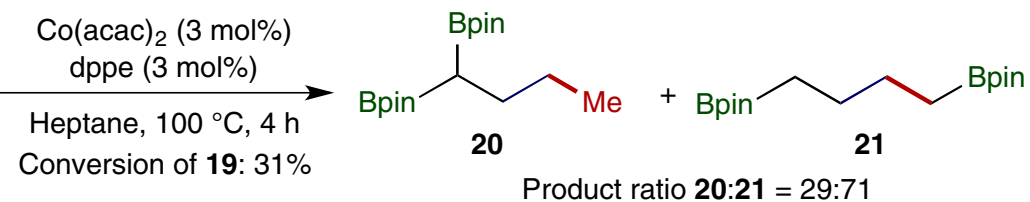

Fig. 7 Chaining-walking hydroboration of phenyl- and boryl-containing alkenes. a Hydroboration of alkene 14. b Hydroboration of alkene 17. c Hydroboration of alkene 18. d Hydroboration of alkene 19. e Hydroboration of alkene $\mathbf{1 8}$ catalyzed by Co(acac) $2 /$ dppe. $\mathbf{f}$ Hydroboration of alkene $\mathbf{1 9}$ catalyzed by $\mathrm{Co}(\mathrm{acac})_{2} /$ dppe.

$\mathrm{Co}(\mathrm{acac})_{2} / \mathrm{dcpe}$ at $100{ }^{\circ} \mathrm{C}$ to give alkylboroante 15 as a major product together with a trace amount (4\%) of alkylboroante 16, a byproduct from chain-walking hydroboration (Fig. 7a). Similarly, the reaction between $(E)$-but-2-en-1-ylbenzene (17) and HBpin under standard conditions afforded alkylboroante products $\mathbf{1 5}$ and 16, albeit with a low regioselectivity $(15: 16=61: 39)$, and both products were resulted from chain-walking hydroboration (Fig. 7b). But-3-en-1-ylbenzene (18) also underwent this cobaltcatalyzed chain-walking hydroboration, but the major product (16) of this reaction was from the hydroboration of terminal double bond of 18 (Fig. 7c). For comparison, we also conducted the reaction between a boryl-containing terminal alkene 19 and HBpin under standard conditions (Fig. 7d), and the major product, gem-bis(boryl)alkane $\mathbf{2 0}$, was formed by the cobaltcatalyzed chain-walking hydroboration. The results of chainwalking hydrobration reactions conducted with but-3-en-1ylbenzene (18) and but-3-en-1-ylboronic pinacol ester (19) indicate that the Bpin group has a stronger directing ability for chain-walking hydroboration than the phenyl group.

In addition, we also tested a cobalt catalyst generated from Co (acac) $)_{2}$ and dppe (1,2-bis(diphenylphosphino)ethane), a bisphosphine ligand having a similar steric but different electronic property, for hydroboration of terminal alkenes 18 and 19 with
HBpin (Fig. 7e and f). These two reactions proceeded very sluggishly and approximately $30 \%$ of $\mathbf{1 8}$ and $\mathbf{1 9}$ were converted at $100{ }^{\circ} \mathrm{C}$ in $24 \mathrm{~h}$. Interestingly, major products (16 and $\mathbf{2 1}$ ) of these two reactions were resulted from direct anti-Markovnikov hydroboration of 18 and 19, and much less byproducts (15 and 20) were formed by chain-walking hydroboration relative to the corresponding reactions catalyzed by the cobalt catalyst generated from $\mathrm{Co}(\mathrm{acac})_{2}$ and dcpe (Fig. 7c, d). The results of these four reactions (Fig. $7 \mathrm{c}-\mathrm{f}$ ) suggest that the electron-rich property of dcpe ligand facilitates the chain-walking process, thus promoting chain-walking hydroboration.

Based on the results of mechanistic studies, we proposed a catalytic pathway for this cobalt-catalyzed chain-walking double hydroboration of 1,4-diene $\mathbf{1 b}$, as depicted in Fig. 8. The activation of $\mathrm{Co}(\mathrm{acac})_{2}$ with HBpin in the presence of dcpe $(\mathbf{L})$ forms a cobalt hydride species (L)Co-H (ref. ${ }^{69}$ ). Migratory insertion of the terminal alkene of $\mathbf{1 b}$ into $(\mathbf{L}) \mathrm{Co}-\mathrm{H}$ generates an alkenylcobalt intermediate $\mathbf{A}$, which then undergoes $\sigma$-bond metathesis with HBpin to produce alkenylboronate $\mathbf{2} \mathbf{b}^{\prime}$ and regenerates $(\mathbf{L}) \mathrm{Co}-\mathrm{H}$. The double bond in $\mathbf{2} \mathbf{b}^{\prime}$ then inserts into $(\mathbf{L}) \mathrm{Co}-\mathrm{H}$ to form an alkylcobalt species $\mathbf{B}$, which undergoes isomerization to form the alkylcobalt intermediate $\mathbf{C}$ through reversible $\beta$-hydrogen elimination and reinsertion. In the last step, $\sigma$-bond metathesis between alkylcobalt species 


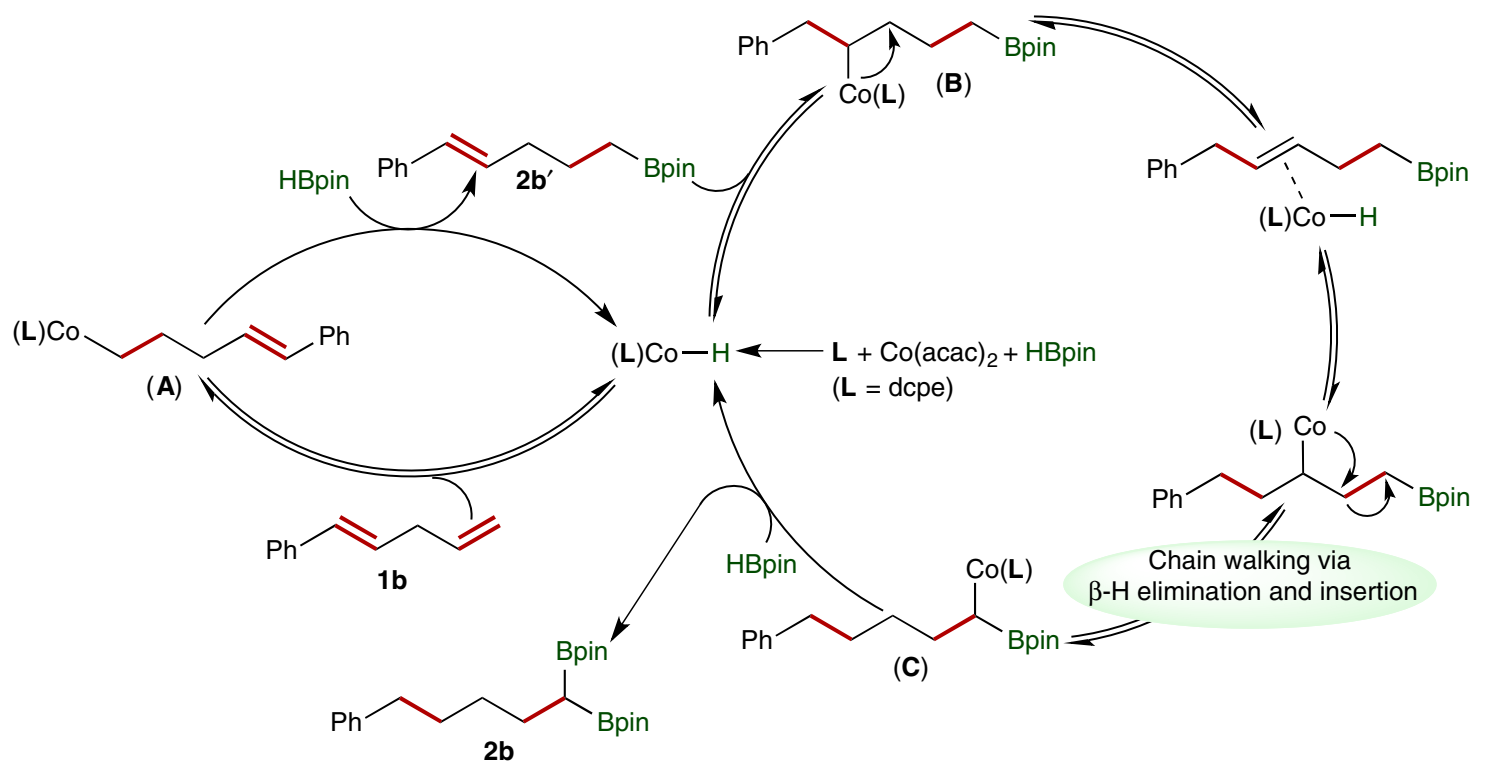

Fig. 8 Proposed mechanism. The proposed catalytic cycle for this cobalt-catalyzed chain-walking double hydroboration.

$\mathbf{C}$ and HBpin yields gem-bis(boryl)alkane $\mathbf{2 b}$ and regenerates the catalytically active $(\mathbf{L}) \mathrm{Co}-\mathrm{H}$ intermediate.

In summary, we have developed an effective and convenient protocol to prepare gem-bis(boryl)alkanes via a selective cobaltcatalyzed double hydroboration of $1, n$-dienes. A wide range of conjugated and non-conjugated $1, n$-dienes reacted with pinacolborane to produce gem-bis(boryl)alkanes in high isolated yields with excellent regioselectivity in the presence of a catalyst generated in situ from $\mathrm{Co}(\mathrm{acac})_{2}$ and dcpe ligand. Mechanistic studies suggest that this cobalt-catalyzed double hydroboration occurs through an initial anti-Markovnikov monohydroboration of $1, n$-dienes followed by a sequential boryl-directed chainwalking hydroboration of the resulting alkenylboronates. This cobalt-catalyzed double hydroboration provides a straightforward approach to access structurally diverse and synthetically versatile gem-bis(boryl)alkanes from readily available 1,n-dienes.

\section{Methods}

General procedure for double hydroboration of 1,n-dienes. In an Argon-filled glovebox, a 4-mL screw-capped vial was charged with $\mathrm{Co}(\mathrm{acac})_{2}(0.8 \mathrm{mg}, 3.0 \mu \mathrm{mol})$, dcpe $(1.3 \mathrm{mg}, 3.0 \mu \mathrm{mol}), 1, \mathrm{n}$-diene $(0.30 \mathrm{mmol})$, heptane $(0.5 \mathrm{~mL})$ and a magnetic stirring bar. The solution was stirred for $5 \mathrm{~min}$ and pincolborane $(96.0 \mathrm{mg}, 0.75 \mathrm{mmol})$ was added to the vial. The vial was sealed with a cap containing a PTFE septum and removed from the glovebox. The mixture was then heated at $100^{\circ} \mathrm{C}$ for $4 \mathrm{~h}$ until complete consumption of starting material as monitored by TLC and GC-MS analysis. Subsequently, the solvent was removed under reduced pressure. The residue was purified by silica gel flash column chromatography (hexane/ethyl acetate $=40: 1$ ) to afford the desired products. See the Supplementary Information for detailed experimental procedures and the characterization data of all the products.

\section{Data availability}

The authors declare that all data supporting the findings of this study are available within the article and Supplementary Information files, and also are available from the corresponding author upon reasonable request.

Received: 18 September 2019; Accepted: 16 January 2020; Published online: 07 February 2020

\section{References}

1. Miyaura, N. \& Suzuki, A. Palladium-catalyzed cross-coupling reactions of organoboron compounds. Chem. Rev. 95, 2457-2483 (1995).

2. Brooks, W. L. A. \& Sumerlin, B. S. Synthesis and applications of boronic acidcontaining polymers: from materials to medicine. Chem. Rev. 116, 1375-1397 (2016).
3. Miralles, N., Maza, R. J. \& Fernández, E. Synthesis and reactivity of 1,1diborylalkanes towards C-C bond formation and related mechanisms. $A d v$. Synth. Catal. 360, 1306-1327 (2018).

4. Nallagonda, R., Padala, K. \& Masarwa, A. gem-Diborylalkanes: recent advances in their preparation, transformation and application. Org. Biomol. Chem. 16, 1050-1064 (2018).

5. Wu, C. \& Wang, J. Geminal bis(boron) compounds: their preparation and synthetic applications. Tetrahedron Lett. 59, 2128-2140 (2018).

6. Marek, I. \& Normant, J.-F. Synthesis and reactivity of $\mathrm{sp}^{3}$ germinated organobismetallics. Chem. Rev. 96, 3241-3267 (1996).

7. Marek, I. Synthesis and reactivity of $\mathrm{sp}^{2}$ germinated organobismetallics. Chem. Rev. 100, 2887-2900 (2000).

8. Li, H. et al. Palladium(0)-catalyzed cross-coupling of 1,1-diboronates with vinyl bromides and 1,1-dibromoalkenes. Angew. Chem. Int. Ed. 53, 11921-11925 (2014)

9. Potter, B., Edelstein, E. K. \& Morken, J. P. Modular, catalytic enantioselective construction of quaternary carbon stereocenters by sequential cross-coupling reactions. Org. Lett. 18, 3286-3289 (2016).

10. Stephens, T. C. \& Pattison, G. Transition-metal-free homologative crosscoupling of aldehydes and ketones with geminal bis(boron) compounds. Org. Lett. 19, 3498-3501 (2017).

11. Hong, K., Liu, X. \& Morken, J. P. Simple access to elusive a-boryl carbanions and their alkylation: an umpolung construction for organic synthesis. J. Am. Chem. Soc. 136, 10581-10584 (2014).

12. Liu, X., Deaton, T. M., Haeffner, F. \& Morken, J. P. A boron alkylidene-alkene cycloaddition reaction: application to the synthesis of aphanamal. Angew. Chem. Int. Ed. 56, 11485-11489 (2017).

13. Masaki, S. et al. Synthesis and applications of 1,1-diborylated cyclopropanes: facile route to 1,2-diboryl-3-methylenecyclopentenes. Chem. Lett. 35, 1222-1223 (2006)

14. Wang, L. et al. C-O functionalization of $\alpha$-oxyboronates: a deoxygenative gem-diborylation and gem-silylborylation of aldehydes and ketones. J. Am. Chem. Soc. 139, 5257-5264 (2017).

15. Lee, Y., Park, J. \& Cho, S. H. Generation and application of (diborylmethyl)zinc (II) species: access to enantioenriched gem-diborylalkanes by an asymmetric allylic substitution. Angew. Chem. Int. Ed. 57, 12930-12934 (2018).

16. Lee, H., Lee, Y. \& Cho, S. H. Palladium-catalyzed chemoselective negishi cross-coupling of bis[(pinacolato)boryl]methylzinc halides with aryl (pseudo) halides. Org. Lett. 21, 5912-5916 (2019).

17. Zhao, B. et al. An olefinic 1,2-boryl-migration enabled by radical addition: construction of gem-bis(boryl)alkanes. Angew. Chem. Int. Ed. 58, 9448-9452 (2019).

18. Endo, K., Hirokami, M. \& Shibata, T. Synthesis of 1,1-organodiboronates via $\mathrm{Rh}(\mathrm{I}) \mathrm{Cl}$-catalyzed sequential regioselective hydroboration of 1-alkynes. Synlett 2009, 1331-1335 (2009).

19. Lee, S., Li, D. \& Yun, J. Copper-catalyzed synthesis of 1,1-diborylalkanes through regioselective dihydroboration of terminal alkynes. Chem. Asian J. 9 , 2440-2443 (2014).

20. Zuo, Z. \& Huang, Z. Synthesis of 1,1-diboronate esters by cobalt-catalyzed sequential hydroboration of terminal alkynes. Org. Chem. Front 3, 434-438 (2016). 
21. Lee, J. C. H., McDonald, R. \& Hall, D. G. Enantioselective preparation and chemoselective cross-coupling of 1,1-diboron compounds. Nat. Chem. 3, 894 (2011).

22. Feng, X., Jeon, H. \& Yun, J. Regio- and enantioselective copper(I)-catalyzed hydroboration of borylalkenes: asymmetric synthesis of 1,1-diborylalkanes. Angew. Chem. Int. Ed. 52, 3989-3992 (2013)

23. Li, L., Gong, T., Lu, X., Xiao, B. \& Fu, Y. Nickel-catalyzed synthesis of 1,1diborylalkanes from terminal alkenes. Nat. Commun. 8, 345 (2017).

24. Teo, W. J. \& Ge, S. Cobalt-catalyzed diborylation of 1,1-disubstituted vinylarenes: a practical route to branched gem-bis(boryl)alkanes. Angew. Chem. Int. Ed. 57, 1654-1658 (2018).

25. Teo, W. J. \& Ge, S. Cobalt-catalyzed enantioselective synthesis of chiral gembis(boryl)alkanes. Angew. Chem. Int. Ed. 57, 12935-12939 (2018).

26. Cho, S. H. \& Hartwig, J. F. Iridium-catalyzed diborylation of benzylic C-H bonds directed by a hydrosilyl group: synthesis of 1,1-benzyldiboronate esters. Chem. Sci. 5, 694-698 (2014).

27. Palmer, W. N., Obligacion, J. V., Pappas, I. \& Chirik, P. J. Cobalt-catalyzed benzylic borylation: enabling polyborylation and functionalization of remote, unactivated C(sp3)-H bonds. J. Am. Chem. Soc. 138, 766-769 (2016).

28. Palmer, W. N., Zarate, C. \& Chirik, P. J. Benzyltriboronates: building blocks for diastereoselective carbon-carbon bond formation. J. Am. Chem. Soc. 139, 2589-2592 (2017).

29. Yamamoto, T., Ishibashi, A., Suginome, M., Boryl-directed \& Ir-catalyzed, C. (sp3)-H borylation of alkylboronic acids leading to site-selective synthesis of polyborylalkanes. Org. Lett. 21, 6235-6240 (2019).

30. Wu, J. Y., Moreau, B. \& Ritter, T. Iron-catalyzed 1,4-hydroboration of 1,3dienes. J. Am. Chem. Soc. 131, 12915-12917 (2009).

31. Ely, R. J. \& Morken, J. P. Regio- and stereoselective ni-catalyzed 1,4 hydroboration of 1,3-dienes: access to stereodefined $(Z)$-allylboron reagents and derived allylic alcohols. J. Am. Chem. Soc. 132, 2534-2535 (2010).

32. Cao, Y. et al. Selective synthesis of secondary benzylic $(Z)$-allylboronates by Fe-catalyzed 1,4-hydroboration of 1-aryl-substituted 1,3-dienes. Org. Chem. Front. 1, 1101-1106 (2014).

33. Fiorito, D. \& Mazet, C. Ir-catalyzed selective hydroboration of 2-substituted 1,3-dienes: a general method to access homoallylic boronates. ACS Catal. 8, 9382-9387 (2018).

34. Duvvuri, K. et al. Cationic Co(I)-intermediates for hydrofunctionalization reactions: regio- and enantioselective cobalt-catalyzed 1,2-hydroboration of 1,3-dienes. J. Am. Chem. Soc. 141, 7365-7375 (2019).

35. Peng, S., Yang, J., Liu, G. \& Huang, Z. Ligand controlled cobalt catalyzed regiodivergent 1,2-hydroboration of 1,3-dienes. Sci. China Chem. 62, 336-340 (2019).

36. Matsumoto, Y. \& Hayashi, T. Asymmetric double hydroboration of 1,3-dienes catalyzed by chiral phosphine-rhodium complexes. Tetrahedron Lett. 32, 3387-3390 (1991).

37. Bair, J. S. et al. Linear-selective hydroarylation of unactivated terminal and internal olefins with trifluoromethyl-substituted arenes. J. Am. Chem. Soc. 136, 13098-13101 (2014).

38. Larionov, E., Li, H. \& Mazet, C. Well-defined transition metal hydrides in catalytic isomerizations. Chem. Commun. 50, 9816-9826 (2014).

39. Larionov, E., Lin, L., Guénée, L. \& Mazet, C. Scope and mechanism in palladium-catalyzed isomerizations of highly substituted allylic, homoallylic, and alkenyl alcohols. J. Am. Chem. Soc. 136, 16882-16894 (2014).

40. Mei, T.-S., Patel, H. H. \& Sigman, M. S. Enantioselective construction of remote quaternary stereocentres. Nature 508, 340 (2014).

41. Yamakawa, T. \& Yoshikai, N. Alkene isomerization-hydroarylation tandem catalysis: indole C2-alkylation with aryl-substituted alkenes leading to 1,1diarylalkanes. Chem. Asian J. 9, 1242-1246 (2014).

42. Buslov, I., Becouse, J., Mazza, S., Montandon-Clerc, M. \& Hu, X. Chemoselective alkene hydrosilylation catalyzed by nickel pincer complexes. Angew. Chem. Int. Ed. 54, 14523-14526 (2015).

43. Dupuy, S., Zhang, K.-F., Goutierre, A.-S. \& Baudoin, O. Terminal-selective functionalization of alkyl chains by regioconvergent cross-coupling. Angew. Chem. Int. Ed. 55, 14793-14797 (2016).

44. Lin, L., Romano, C. \& Mazet, C. Palladium-catalyzed long-range deconjugative isomerization of highly substituted $\alpha, \beta$-unsaturated carbonyl compounds. J. Am. Chem. Soc. 138, 10344-10350 (2016).

45. Vasseur, A., Bruffaerts, J. \& Marek, I. Remote functionalization through alkene isomerization. Nat. Chem. 8, 209 (2016).

46. Chen, F. et al. Remote migratory cross-electrophile coupling and olefin hydroarylation reactions enabled by in situ generation of NiH. J. Am. Chem. Soc. 139, 13929-13935 (2017).

47. Gaydou, M., Moragas, T., Juliá-Hernández, F. \& Martin, R. Site-selective catalytic carboxylation of unsaturated hydrocarbons with $\mathrm{CO}_{2}$ and water. $J$. Am. Chem. Soc. 139, 12161-12164 (2017).
48. He, Y., Cai, Y. \& Zhu, S. Mild and regioselective benzylic C-H functionalization: $\mathrm{Ni}$-catalyzed reductive arylation of remote and proximal olefins. J. Am. Chem. Soc. 139, 1061-1064 (2017)

49. Juliá-Hernández, F., Moragas, T., Cornella, J. \& Martin, R. Remote carboxylation of halogenated aliphatic hydrocarbons with carbon dioxide. Nature 545, 84 (2017).

50. Singh, S., Bruffaerts, J., Vasseur, A. \& Marek, I. A unique pd-catalysed heck arylation as a remote trigger for cyclopropane selective ring-opening. Nat. Commun. 8, 14200 (2017)

51. Peng, L. et al. Ligand-controlled nickel-catalyzed reductive relay crosscoupling of alkyl bromides and aryl bromides. ACS Catal. 8, 310-313 (2018).

52. Sommer, H., Juliá-Hernández, F., Martin, R. \& Marek, I. Walking metals for remote functionalization. ACS Centr. Sci. 4, 153-165 (2018).

53. Wang, Z., Yin, H. \& Fu, G. C. Catalytic enantioconvergent coupling of secondary and tertiary electrophiles with olefins. Nature 563, 379-383 (2018)

54. Zhang, Y., Han, B. \& Zhu, S. Rapid access to highly functionalized alkyl boronates by $\mathrm{NiH}$-catalyzed remote hydroarylation of boron-containing alkenes. Angew. Chem. Int. Ed. 58, 13860-13864 (2019).

55. Obligacion, J. V. \& Chirik, P. J. Bis(imino)pyridine cobalt-catalyzed alkene isomerization-hydroboration: a strategy for remote hydrofunctionalization with terminal selectivity. J. Am. Chem. Soc. 135, 19107-19110 (2013).

56. Chen, C., Dugan, T. R., Brennessel, W. W., Weix, D. J. \& Holland, P. L. Zselective alkene isomerization by high-spin cobalt(II) complexes. J. Am. Chem. Soc. 136, 945-955 (2014).

57. Ruddy, A. J., Sydora, O. L., Small, B. L., Stradiotto, M. \& Turculet, L. (Nphosphinoamidinate) cobalt-catalyzed hydroboration: alkene isomerization affords terminal selectivity. Chemistry 20, 13918-13922 (2014).

58. Palmer, W. N., Diao, T., Pappas, I. \& Chirik, P. J. High-activity cobalt catalysts for alkene hydroboration with electronically responsive terpyridine and $a-$ diimine ligands. ACS Catal. 5, 622-626 (2015).

59. Scheuermann, M. L., Johnson, E. J. \& Chirik, P. J. Alkene isomerization-hydroboration promoted by phosphine-ligated cobalt catalysts. Org. Lett. 17, 2716-2719 (2015)

60. Peng, J., Docherty, J. H., Dominey, A. P. \& Thomas, S. P. Cobalt-catalysed Markovnikov selective hydroboration of vinylarenes. Chem. Commun. 53, 4726-4729 (2017)

61. Chen, X., Cheng, Z., Guo, J. \& Lu, Z. Asymmetric remote C-H borylation of internal alkenes via alkene isomerization. Nat. Commun. 9, 3939 (2018).

62. Liu, X. et al. Cobalt-catalyzed regioselective olefin isomerization under kinetic control. J. Am. Chem. Soc. 140, 6873-6882 (2018).

63. Meng, Q.-Y., Schirmer, T. E., Katou, K. \& König, B. Controllable isomerization of alkenes by dual visible-light-cobalt catalysis. Angew. Chem. Int. Ed. 58, 5723-5728 (2019).

64. Yu, S., Wu, C. \& Ge, S. Cobalt-catalyzed asymmetric hydroboration/ cyclization of 1,6-enynes with pinacolborane. J. Am. Chem. Soc. 139, 6526-6529 (2017)

65. Wang, C. \& Ge, S. Versatile cobalt-catalyzed enantioselective entry to borylfunctionalized all-carbon quaternary stereogenic centers. J. Am. Chem. Soc. 140, 10687-10690 (2018)

66. Wu, C., Liao, J. \& Ge, S. Cobalt-catalyzed enantioselective hydroboration/ cyclization of 1,7-enynes: asymmetric synthesis of chiral quinolinones containing quaternary stereogenic centers. Angew. Chem. Int. Ed. 58, 8882-8886 (2019)

67. Jo, W., Kim, J., Choi, S. \& Cho, S. H. Transition-metal-free regioselective alkylation of pyridine $\mathrm{N}$-oxides using 1,1-diborylalkanes as alkylating reagents. Angew. Chem. Int. Ed. 55, 9690-9694 (2016).

68. Green, M. L. H. A new approach to the formal classification of covalent compounds of the elements. J. Organomet. Chem. 500, 127-148 (1995).

69. Ai, W., Zhong, R., Liu, X. \& Liu, Q. Hydride transfer reactions catalyzed by cobalt complexes. Chem. Rev. 119, 2876-2953 (2019).

\section{Acknowledgements}

This work was supported by the grant from the Ministry of Education of Singapore (R143-000-A07-112 and R-143-000-A93-112).

\section{Author contributions}

M.H. planned and conducted most of the experiments. S.G. directed the projects, and S.G. and M.H. co-wrote the manuscript. Both authors contributed to the discussion.

\section{Competing interests}

The authors declare no competing interests. 


\section{Additional information}

Supplementary information is available for this paper at https://doi.org/10.1038/s41467020-14543-2.

Correspondence and requests for materials should be addressed to S.G.

Peer review information Nature Communications thanks Ilan Marek, Naohiko Yoshikai and the other, anonymous, reviewer(s) for their contribution to the peer review of this work.

Reprints and permission information is available at http://www.nature.com/reprints

Publisher's note Springer Nature remains neutral with regard to jurisdictional claims in published maps and institutional affiliations. (c) (i) Open Access This article is licensed under a Creative Commons Attribution 4.0 International License, which permits use, sharing, adaptation, distribution and reproduction in any medium or format, as long as you give appropriate credit to the original author(s) and the source, provide a link to the Creative Commons license, and indicate if changes were made. The images or other third party material in this article are included in the article's Creative Commons license, unless indicated otherwise in a credit line to the material. If material is not included in the article's Creative Commons license and your intended use is not permitted by statutory regulation or exceeds the permitted use, you will need to obtain permission directly from the copyright holder. To view a copy of this license, visit http://creativecommons.org/ licenses/by/4.0/.

(C) The Author(s) 2020 